\title{
Objetos de Aprendizagem Plugados e Desplugados: um estudo de caso com ordenação alfabética
}

\author{
Cláudia Werlich ${ }^{1,3,4}$, Lucas Fagundes Torrá ${ }^{2}$, Cristiani Crema ${ }^{1}$, Isabela Gasparini ${ }^{1,2}$, \\ Avanilde Kemczinski ${ }^{1,2}$ \\ ${ }^{1}$ PPGECMT e ${ }^{2}$ PPGCA, Departamento de Ciência da Computação (DCC) \\ Universidade do Estado de Santa Catarina (UDESC) - Joinville, SC - Brasil \\ ${ }^{3}$ Faculdade Anhanguera - Joinville, SC - Brasil \\ ${ }^{4}$ Faculdade Senac Joinville - Joinville, SC - Brasil \\ \{clawer,crisitani.crema\}@gmail.com, lucasgabrielft@hotmail.com \\ \{isabela.gasparini, avanilde.kemczinski\}@udesc.br
}

\begin{abstract}
Learning Objects (LO) have a pedagogical purpose and are reusable, adapting to the needs, abilities, interest and learning style of both the students and the teacher. This article describes a case study carried out with the objective of applying alphabetically arranged LOs developed in an unplugged form (Ordering Wand) and plugged (Lettering Application). The methodology used for the construction and evaluation of LOs was the ADDIE model. As a result, it was found that students expressed distinct preferences regarding LOs. It was noticed that the students had greater ease of use and better performance in the unplugged activity than in the plugged activity.
\end{abstract}

Resumo. Objetos de Aprendizagem (OA) possuem um objetivo pedagógico e são reutilizáveis, adaptando-se às necessidades, habilidades, interesse e estilo de aprendizagem, tanto dos alunos quanto do professor. Esse artigo descreve um estudo de caso realizado com o objetivo de aplicar os OAs de ordenação alfabética desenvolvidos de forma desplugada (Varal de Ordenação) e plugada (Aplicativo de Ordenação de Letras). A metodologia utilizada para a construção e avaliação dos OAs foi o modelo ADDIE. Como resultado constatou-se que os estudantes manifestaram preferências distintas quanto aos OAs. Percebeu-se que os estudantes tiveram maior facilidade de uso e melhor desempenho na atividade desplugada do que na atividade plugada.

\section{Introdução}

A tecnologia está a cada dia se integrando nos processos educacionais, aumentando significativamente as possibilidades para o desenvolvimento de conteúdos pedagógicoinstrucionais (GARCIA et al., 2015). O Design Instrucional é identificado como uma metodologia educacional capaz de se valer da tecnologia para propor práticas e soluções para uma aprendizagem colaborativa, autônoma, que atenda às necessidades da sociedade da informação e do conhecimento, conforme Batista (2008).

Filatro (2010) assegura que o Design Instrucional “[...] é o planejamento, o desenvolvimento e a utilização de métodos, técnicas, atividades, materiais, eventos e produtos educacionais em situações didáticas específicas, a fim de facilitar a aprendizagem humana a partir dos princípios de aprendizagem e instrução conhecidos”. Portanto, o Design Instrucional serve para a construção de qualquer material que facilite o processo de educação e aprendizagem. 
VIII Congresso Brasileiro de Informática na Educação (CBIE 2019)

Anais do XXV Workshop de Informática na Escola (WIE 2019)

Balbino (2007) estabelece que os OAs são definidos como uma entidade digital ou não digital, a qual pode ser utilizada, reutilizada ou referenciada durante um processo de suporte tecnológico ao ensino e aprendizagem. A partir da motivação para a resolução de problemas, o uso de OAs oportuniza ao aluno conhecer novas ferramentas, testar diferentes situações, compreender a relação entre causa e efeito de conceitos e fenômenos (RIVED, 2018). Os OAs são desenvolvidos com início, meio e fim, podendo ser aplicados em diversas situações de aprendizagem e reutilizados.

Este artigo descreve um estudo de caso realizado na disciplina de Pensamento Computacional em uma escola particular de Ensino Fundamental I, situada em Joinville Santa Catarina. O objetivo do estudo de caso foi aplicar os Objetos de Aprendizagem de Ordenação de Letras de forma desplugada, com uso de objeto físico e também de maneira plugada, com o auxílio de um aplicativo de celular.

Para contextualizar o processo e os resultados encontrados descrevemos a fundamentação teórica na Seção 2. Em seguida, na Seção 3, descrevemos a metodologia aplicada na atividade de estudo de caso. Na Seção 4, mostramos os resultados obtidos. Por fim, realizamos as considerações finais na Seção 5, seguida das referências bibliográficas.

\section{Design Instrucional do Objeto de Aprendizagem}

O Design Instrucional (DI) é uma tecnologia utilizada na educação e, por isso, precisa de métodos que sustentem sua aplicação de forma prática. Um destes métodos, conforme Filatro (2008), é o modelo ADDIE, acrônimo de: Analisar (A - Analyze); Estruturar (D Design); Desenvolver (D - Development); Implementar (I - Implement); Avaliar (E Evaluate), sendo cada uma destas etapas é focada a uma fase do planejamento educacional.

Utilizando a metodologia ADDIE, foram desenvolvidos dois Objetos de Aprendizagem de Ordenação Alfabética: Varal de Ordenação de Letras e um Aplicativo de celular de Ordenação de Letras, com o objetivo pedagógico de verificar as habilidades dos estudantes (em fase de alfabetização) em conhecer o alfabeto e a sua ordem alfabetização. O Varal de Ordenação de Letras foi fundamentado na Computação Desplugada, utilizando letras impressas. As letras são distribuídas aleatoriamente na mesa e a criança deve prender no varal as letras ordenadas alfabeticamente. Por ser de baixo custo, esse OA apresenta adaptabilidade às necessidades socioeconômicas, sendo acessível a diversos públicos alvos. O Aplicativo de celular que permite a Ordenação das Letras, foi desenvolvido para a plataforma Android e sua funcionalidade principal é a de reproduzir a funcionalidade do Varal de Ordenação, numa versão informatizada e encontra-se disponível gratuitamente para download no seguinte link: https://goo.gl/TmDrF3.

\subsection{Fase de Análise}

Dentro da metodologia ADDIE, a fase de Análise tem como finalidade analisar o públicoalvo, suas necessidades, os objetivos de aprendizagem e a avaliação de métricas. Segundo Filatro (2008), os procedimentos para essa fase são realizados: "por meio da análise contextual, que abrange o levantamento das necessidades educacionais propriamente ditas, a caracterização dos alunos e a verificação de restrições”.

Os OAs possuem a finalidade de atingir a um determinado objetivo pedagógico e por serem reutilizáveis e versáteis, podem se adaptar às necessidades, interesses e estilos de aprendizagem, tanto dos alunos quanto do professor. Possibilitam a criação de situações práticas e reais, tornando a aprendizagem significativa. Moreira (2015) define a 
VIII Congresso Brasileiro de Informática na Educação (CBIE 2019)

Anais do XXV Workshop de Informática na Escola (WIE 2019)

aprendizagem significativa como o processo pelo qual uma nova informação relaciona-se com um aspecto especificamente relevante da estrutura do conhecimento do estudante, havendo uma interação de uma nova informação com uma estrutura de conhecimento específica existente. Desta forma novos conhecimentos podem ser aprendidos à medida que conceitos relevantes e também inclusivos estejam claros e disponíveis na estrutura cognitiva do aluno.

Algumas vantagens pedagógicas do uso de OA podem ser elencadas, conforme Tarouco et al. (2014): (i) Motivação do processo ensino-aprendizagem; (ii) Estimular o pensamento indutivo; (iii) Estimular o pensamento dedutivo; (iv) Estimular a construção de hipóteses; (v) Simulações de situações reais; (vi) A possibilidade de aplicação em diferentes realidades e contextos. De acordo com Kemczinski et al. (2012) os OAs devem atender a maioria das características técnicas e pedagógicas que compreendem o processo educacional, é importante que esses objetos apresentem interatividade, venham a estimular a autonomia e cooperação, favorecerem a cognição e o afeto, sem, no entanto descurar da articulação com as características técnicas de adaptabilidade, de agregação e classificação, do aspecto digital, da durabilidade, interoperabilidade e reusabilidade.

Filatro (2010) afirma que "[...] a aprendizagem é comprovada por meio de respostas corretas". A teoria de aprendizagem que tange a prática docente na aplicação desses objetos de aprendizagem é o Instrucionismo. Os OAs que apresentam características com questões e ou problemas, com feedback imediato, e que podem ser trabalhados de forma individual, assemelham-se a proposta da máquina de ensinar, como afirma Tarouco et al. (2014). Partindo dessa perspectiva nos OAs desenvolvidos, o aluno receberá um feedback imediato da sua assertividade na tentativa de ordenação alfabética, tanto no Varal de Ordenação quanto no Aplicativo, sendo no varal o responsável pelo feedback o professor e no aplicativo esse processo é automatizado.

A partir da metodologia apresentada, foram definidos os seguintes objetivos pedagógicos dos OAs para Ordenação de Letras: (i) Reforçar a sequência crescente alfabética utilizando os OAs de forma plugada e desplugada; (ii) Possibilitar ao aluno o aprendizado de forma dinâmica a partir dos OA; (iii) Permitir a fixação da ordenação correta das letras; e (iv) Avaliar o desempenho dos alunos de acordo com a atividade proposta, mensurando a quantidade de erros e acertos em cada OAs.

\subsection{Fase de Design}

Ishikawa (2018) afirma que a fase de Design ocorre simultaneamente com a fase de análise com propósito de realizar as alterações necessárias antes do desenvolvimento do objeto de aprendizagem. "Compreende basicamente os planos de construção do cenário, objetivos de formação, modelos, o sequenciamento de conteúdo, a seleção de mídias, usa habilidade e requisitos de avaliação" ISHIKAWA (2018).

Filatro (2008) enfatiza que a Matriz de Design Instrucional organiza todas as informações básicas do processo educacional de uma forma tabular, dividindo em unidades de aprendizagem. A autora ainda afirma que "[...] por meio da matriz, podemos definir quais atividades serão necessárias para atingir os objetivos, bem como elencar quais conteúdos e ferramentas serão precisos para realização das atividades", conforme pode ser observado no Quadro 1. 
VIII Congresso Brasileiro de Informática na Educação (CBIE 2019)

Anais do XXV Workshop de Informática na Escola (WIE 2019)

Quadro 1. Matriz Instrucional dos Objetos de Aprendizagem

\begin{tabular}{|c|c|c|c|c|c|c|c|}
\hline Unidade & Objetivos & Papéis & Atividades & Duração & Ferramentas & Conteúdos & Avaliação \\
\hline 1 & $\begin{array}{c}\text { Identificar e } \\
\text { reforçar a } \\
\text { ordenação } \\
\text { alfabética } \\
\text { crescente } \\
\text { Sortear a } \\
\text { sequência de } \\
\text { letras para a } \\
\text { ordenação. }\end{array}$ & $\begin{array}{l}\text { Professor: } \\
\text { Incentivador } \\
\text { Mediador } \\
\text { Sanar dúvidas. } \\
\text { Aluno: } \\
\text { Participar das } \\
\text { atividades. }\end{array}$ & $\begin{array}{l}\text { Aula } \\
\text { Prática. }\end{array}$ & $\begin{array}{c}1 \text { aula de } 45 \\
\text { Minutos. } \\
\\
5 \text { minutos } \\
\text { para cada } \\
\text { aluno. }\end{array}$ & $\begin{array}{l}\text { Varal de } \\
\text { Ordenação } \\
\text { Letras do } \\
\text { Alfabeto } \\
\text { Grampos } \\
\text { Celular com } \\
\text { aplicativo }\end{array}$ & $\begin{array}{l}\text { Sequência } \\
\text { alfabética }\end{array}$ & Dialógica \\
\hline 2 & $\begin{array}{c}\text { Verificar a } \\
\text { assertividade. }\end{array}$ & \begin{tabular}{|c} 
Professor \\
Verificar se a \\
ordem alfabética \\
está correta. \\
Incentivar os \\
alunos para \\
tentar acertar. \\
Aluno \\
Verificar e \\
arrumar até \\
atingir a ordem \\
correta da \\
ordenação \\
alfabética.
\end{tabular} & $\begin{array}{l}\text { Aula } \\
\text { Prática }\end{array}$ & $\begin{array}{l}\text { Término da } \\
\text { ordenação }\end{array}$ & $\begin{array}{c}\text { Varal de } \\
\text { Ordenação } \\
\text { Letras do } \\
\text { Alfabeto } \\
\text { Grampos } \\
\text { Celular com } \\
\text { Aplicativo. }\end{array}$ & $\begin{array}{l}\text { Sequência } \\
\text { alfabética. }\end{array}$ & $\begin{array}{c}\text { Verificação da } \\
\text { quantidade de } \\
\text { tentativas para } \\
\text { atingir a } \\
\text { ordenação } \\
\text { correta. }\end{array}$ \\
\hline
\end{tabular}

Romiszowski e Romiszowski (2005) afirmam que o formato do material instrucional elaborado depende do tipo de conteúdo abordado e a ser apresentado, do objetivo de aprendizagem a ser trabalhado e da caracterização do público alvo. A Unidade de Aprendizagem é definida, segundo Filatro (2010), como uma unidade elementar que contém os elementos necessários ao processo de ensino-aprendizagem. A Unidade não pode ser subdividida sem perder significado e tem tempo e extensão limitados, buscando atingir os objetivos de aprendizagem pretendidos, apoiada por conteúdos e ferramentas.

O processo de realização do OA de Ordenação começou com a realização de um storyboard, que tem como finalidade descrever detalhes da sequência dos Objetos de Aprendizagem a serem desenvolvidos, sendo demonstrados na Figura 1.

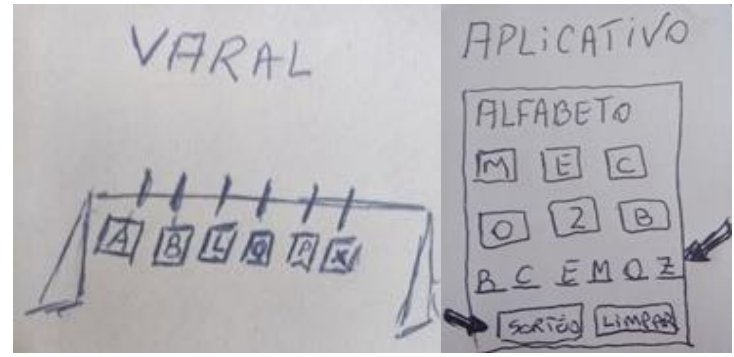

Figura 1. Storyboard dos Objetos de Aprendizagem

Para elaborar o Aplicativo de Ordenação de Letras foi elaborado um diagrama de sequência. Guedes (2011) salienta que o diagrama de sequência é um diagrama comportamental, com a finalidade de estabelecer uma ordem temporal em que as mensagens são trocadas em um determinado processo, mostrando uma sequência de atividades entre $o$ ponto inicial até o ponto final da atividade. Conforme a Figura 2, as etapas do diagrama de sequência do Aplicativo desenvolvido são: (i) $\mathrm{O}$ aplicativo deve disponibilizar para $\mathrm{o}$ usuário (aluno) seis botões, cada botão contém uma letra e a ordem é distribuída de forma randômica; (ii) $\mathrm{O}$ aluno deve clicar nos botões de acordo com a sequência alfabética que ele 
VIII Congresso Brasileiro de Informática na Educação (CBIE 2019)

Anais do XXV Workshop de Informática na Escola (WIE 2019)

julga ser correta, o botão é desabilitado quando recebe um clique; (iii) Cada vez que um botão recebe um clique, o aplicativo deve copiar a sua letra para um espaço abaixo, para mostrar ao aluno a sequência que ele está montando, da mesma forma que é feita no varal de ordenação; (iv) Após todos os botões serem escolhidos, o aplicativo informa ao aluno se a sequência de letras está correta; (v) O aluno recebe o feedback e pode iniciar novamente se desejar. Na tela do aplicativo também existe um botão "Limpar", que não segue o fluxo de atividades, esse tem o objetivo de reiniciar a atividade a qualquer momento.

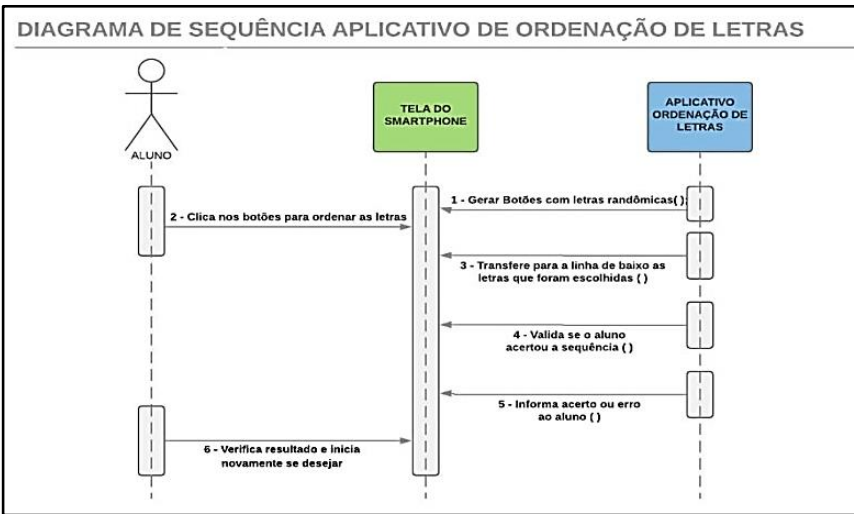

Figura 2. Diagrama de Sequência do Aplicativo de Celular

\section{Objetos de Aprendizagem de Ordenação de Letras}

Os Objetos de Aprendizagem desenvolvidos: Varal de Ordenação o Aplicativo Ordenação de Letras tem o intuito de contribuir no processo de aprendizagem dos estudantes do $2^{\circ}$ ano do Ensino Fundamental I na ordenação crescente do alfabeto.

\subsection{Objeto Desplugado Varal de Ordenação}

O AO Varal de Ordenação foi desenvolvido sem a necessidade do uso de tecnologia, sendo considerada como uma atividade desplugada. $\mathrm{O}$ varal consiste em uma armação de madeira, com um fio de náilon para que os alunos sejam capazes de pendurar as letras em ordem crescente, utilizando um prendedor de roupas. A Figura 3 demonstra o OA Varal de Ordenação de Letras desenvolvido.

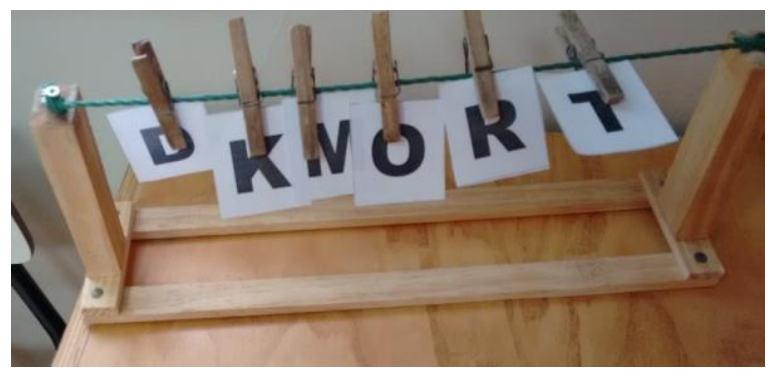

Figura 3. Varal de Ordenação de Letras

O Varal de Ordenação de Letras produzido apresentou baixo custo na sua fabricação, sendo utilizados restos de madeiras que seriam descartados. $O$ varal é versátil, pois pode ser adaptado de diversas formas e com os mais variados tipos de materiais disponíveis. 
VIII Congresso Brasileiro de Informática na Educação (CBIE 2019)

Anais do XXV Workshop de Informática na Escola (WIE 2019)

\subsection{Objeto Plugado Ordenação de Letras}

O aplicativo de Ordenação de Letras tem o mesmo princípio do outro Objeto de Aprendizagem (Varal de Ordenação de Letras), conforme o diagrama de sequência, apresentado na Figura 2. A aplicação foi desenvolvida para smartphones que utilizam o sistema operacional Android.

O Objeto de Aprendizagem conforme Figura 4, funciona da seguinte forma: (i) na tela do aparelho estão dispostos 6 botões com letras geradas randomicamente; (ii) o botão de cada letra é desabilitado quando o aluno clica nele, a letra do botão clicado é mostrada abaixo, para o aluno conseguir verificar a sequência que está sendo montada; (iii) o aluno pode limpar a sequência e iniciar novamente, ou recomeçar a atividade após o feedback que é mostrado na tela quando ele clica no sexto (e último) botão.

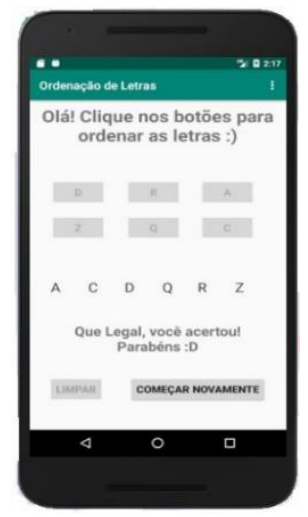

Figura 4. Aplicativo Android de Ordenação de Letras

No desenvolvimento do Aplicativo de Ordenação de Letras utilizou-se a plataforma Android Studio, utilizando a linguagem de programação Java para Android e a Linguagem de Modelagem UML 2.0.

\subsection{Atividade Proposta}

Participaram da pesquisa dez alunos da turma do $2^{\circ}$ ano do Ensino Fundamental I, de uma escola da rede particular de ensino de Joinville - Santa Catarina, todos com idade de oito anos, sendo cinco do sexo feminino e o cinco do sexo masculino. A atividade proposta foi aplicada pela pesquisadora e professora da disciplina de Pensamento Computacional de acordo com os Termos de Consentimento Livre e Esclarecido do Comitê de Ética e Pesquisa com Seres Humanos.

Os alunos participantes da pesquisa receberam instruções iniciais do funcionamento das duas atividades, mas antes de cada aluno utilizar o OA, a explicação foi novamente reforçada. A atividade foi realizada individualmente e de forma livre de controle de tempo. A criança não foi cobrada pelo tempo da atividade com a finalidade de deixar a criança a vontade para realizar a atividade, porém afim de controle, o tempo estipulado foi de cinco minutos para cada criança utilizar os dois Objetos de Aprendizagem.

Cada aluno poderia escolher a ordem de uso de cada OA. Apesar de a escolha ser livre, todos escolheram o Varal de Ordenação (atividade desplugada) como primeira opção. Para o aluno começar a utilizar o Varal de Ordenação era realizado um sorteio de seis letras, após o aluno começava a "pendurar" as letras no Varal na sequência que julgasse ser a ordem correta. A Figura 5 demonstra um aluno utilizando o Varal de Ordenação. 
VIII Congresso Brasileiro de Informática na Educação (CBIE 2019)

Anais do XXV Workshop de Informática na Escola (WIE 2019)

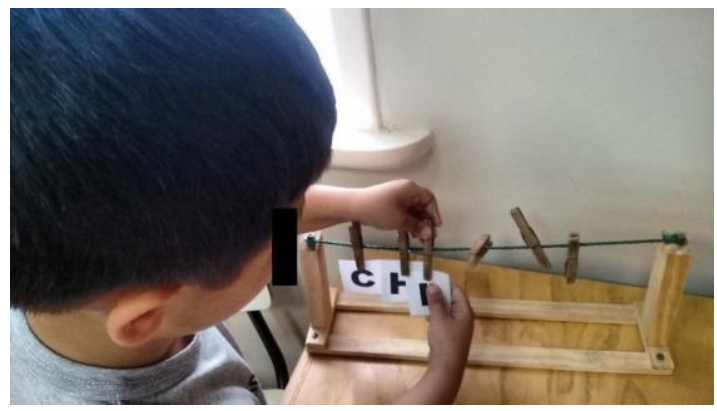

Figura 5. Utilização do Varal de Ordenação

Após a tarefa ser executada no Varal de Ordenação, foi realizada a atividade de ordenar as letras no outro OA, o Aplicativo de Ordenação de Letras (OA plugado). Durante a utilização do aplicativo, notou-se que os alunos, assim que tiveram acesso ao aplicativo, logo clicavam em todos os locais possíveis. Esse fato pode ser devido a curiosidade do uso do smartphone, uma vez que os alunos não possuíam aparelho celular. Após esse primeiro contato com o aplicativo, houve a necessidade de uma nova explicação e todos os alunos executaram a atividade com sucesso, finalizando a tarefa.

\subsection{Coleta de dados - Observação Direta}

Para realizar a coleta dos dados por meio da observação direta, foram definidas algumas questões, com o objetivo de auxiliar a análise individual da atividade proposta: (1) Q1: Após dar início a tarefa, o aluno precisou de ajuda para utilizar os Objetos de Aprendizagem?; (2) Q2: O aluno demorou para utilizar um dos Objetos Aprendizagem ou precisou de intervenção do professor?; (3) Q3: O aluno errou a ordenação? Quantas vezes precisou refazer a atividade para acertar a ordenação?; (4) Q4: O aluno gostou de participar das atividades? Qual dos Objetos de Aprendizagem gostou mais ("o que achou mais legal")?

\section{Resultados}

Um total de 10 estudantes participaram individualmente de cada uma das atividades. $\mathrm{O}$ tempo estipulado pela pesquisadora e professora da turma, foi de 5 minutos para cada aluno, somente uma aluna precisou deste tempo, os demais terminaram antes do tempo estabelecido. A ordem de participação da pesquisa foi aleatória. Esta seção apresenta o resultado de cada questão observada.

Na Q1: “Após dar início a tarefa, o aluno precisou de ajuda para utilizar os Objetos de Aprendizagem?" Duas situações distintas e significativas aconteceram. No OA do Varal (desplugado sem apoio da tecnologia) as crianças manipularam o objeto com facilidade e inclusive ao perceber que tinham errado, arrumavam o varal imediatamente e sem necessidade de intervenção da pesquisadora. No entanto, quatro alunos (40\% do total) precisaram de ajuda para usar o aplicativo no smartphone (mesmo após explicações repetidas). Outro ponto é que $90 \%$ dos estudantes não possuíam o próprio celular e com isso se mostraram um pouco receosos de manuseá-lo no primeiro momento.

Quanto a Questão Q2: “O aluno demorou para utilizar um dos Objetos Aprendizagem ou precisou de intervenção do professor?"; Três meninas (30\% do total) demoraram para ordenar as letras, tanto no Varal quanto no Aplicativo, entretanto, somente uma menina utilizou o tempo máximo de 5 minutos para realizar as atividades. A sequência de letras sorteadas (para as três meninas) não continham vogais. Durante todas as participações observou-se que no momento em que aparecia uma vogal a criança solucionava a ordenação de forma mais rápida e eficaz do que quando existiam apenas consoantes. O papel de mediação da pesquisadora na Q2 ocorreu somente no caso em que o aluno solicitou e quando houve uma demora ou hesitação na ordenação, sendo necessário 
VIII Congresso Brasileiro de Informática na Educação (CBIE 2019)

Anais do XXV Workshop de Informática na Escola (WIE 2019)

um incentivo por meio das seguintes frases: (i) “O que você acha que está errado?"; (ii) "Será que determinada letra está mesmo certa?"; (iii) "Se estiver errado não há problema nenhum, faremos novamente!”.

Para a Q3: "O aluno errou a ordenação? Quantas vezes precisou refazer a atividade para acertar a ordenação?;", oito alunos ( $80 \%$ do total) precisaram no mínimo de duas tentativas para realizar a ordenação no Aplicativo, fato que não ocorreu no Varal de Ordenação. Assim que os alunos seguravam a letra, ao pendurar no Varal de Ordenação, as letras eram posicionadas na posição correta. Já no celular, a precipitação de apertar os botões pode ter interferido e induzido os participantes ao erro. Foi observado a decepção e frustação de ter errado por parte do aluno. No entanto, no aplicativo o aluno precisava fazer a ordenação mental primeiro e clicar na letra de forma ordenada, mas o impulso de clicar primeiro foi o item mais observado. A Figura 6 demostra que o Aplicativo de Ordenação precisou de mais tentativas para obter a assertividade na tarefa de ordenar as letras do que no OA do Varal de Ordenação.

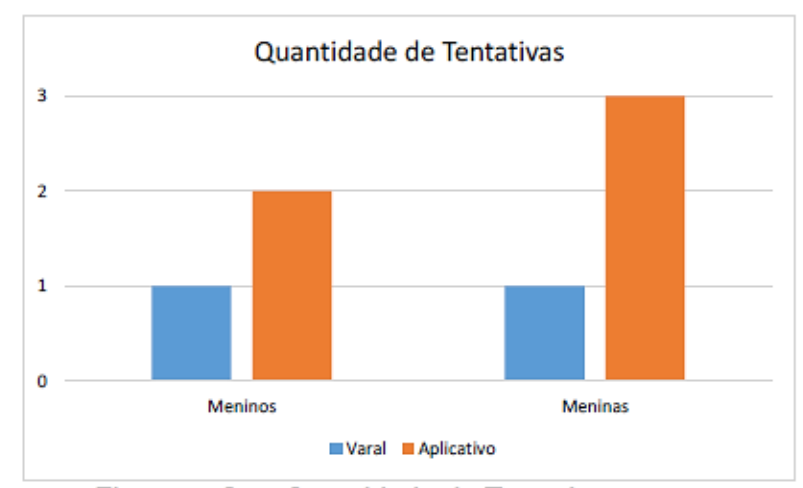

Figura 6. Q3 - Quantidade de tentativas para acertar

$\mathrm{Na}$ Q4: "O aluno gostou de participar das atividades? Qual dos Objetos de Aprendizagem gostou mais (o que achou mais legal)?". Todas as crianças gostaram da atividade e gostariam de refazer. Uma criança pediu um nível mais complexo para o Aplicativo do celular. A Figura 7 demonstra que todos os meninos gostaram mais do Aplicativo do celular e todas as meninas gostaram mais do Varal (empatando em 50\% para cada Objeto de Aprendizagem). Apesar de responderem de forma distinta quanto a qual OA mais gostaram, todos os estudantes optaram por iniciar as atividades pelo Varal de Ordenação.

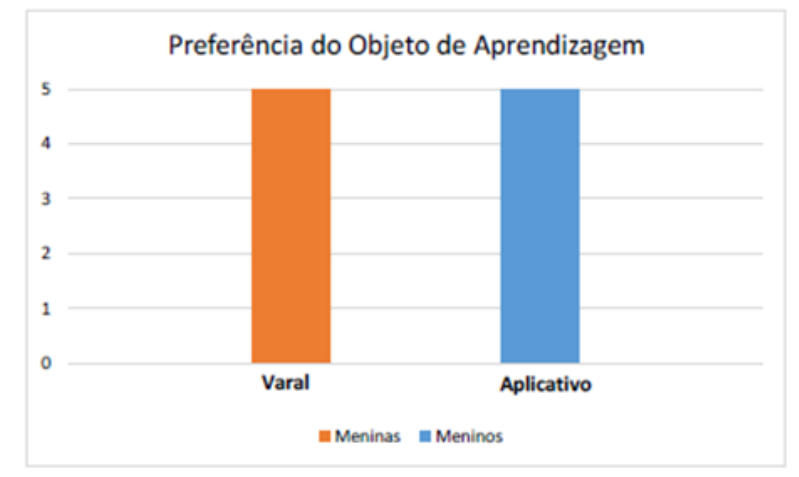

Figura 7. Q4 - Preferência do Objeto de Aprendizagem 
VIII Congresso Brasileiro de Informática na Educação (CBIE 2019)

Anais do XXV Workshop de Informática na Escola (WIE 2019)

\section{Considerações Finais e Trabalhos Futuros}

Neste trabalho buscou-se a aplicação dos Objetos de Aprendizagem desenvolvidos com a metodologia ADDIE. A proposta buscou analisar o uso de OAs plugados e desplugados para estudantes do $2^{\circ}$ ano do Ensino Fundamental. Os dois OAs desenvolvidos são sobre a ordenação crescente das letras do alfabeto. O primeiro OA é o Varal de Ordenação que dispensa o uso de tecnologia, é uma atividade desplugada. O segundo objeto é um aplicativo para celular, aplicativo de Ordenação de Letras.

Ao realizar a atividade, de forma individualizada, os alunos puderam fazer a escolha de qual Objeto de Aprendizagem que gostariam de começar. O Varal de Ordenação foi a atividade que mais "chamou a atenção" dos alunos, sendo a primeira escolha de todos os participantes. O Varal também se mostrou uma boa opção de Ordenação, pois foi o Objeto de Aprendizagem em que os alunos menos tiveram dúvidas na sua utilização e mais sucesso obtiveram na ordenação.

O uso do aplicativo de Ordenação de Letras ocasionou dúvidas sobre a sua utilização principalmente pelo fato do aluno clicar de forma precipitada e de se arrepender, necessitando de uma nova tentativa para realizar a ordenação. Todos os meninos alegaram que gostaram mais de utilizar o aplicativo do que o Varal, fato contrário em relação a opinião das meninas, que preferiram utilizar o Varal. O professor pode fazer uso destes Objetos de Aprendizagem como forma de apoio e estímulo para conhecer a sequência correta das letras. Segundo Vygotsky (1984), o lúdico desempenha um papel fundamental no desenvolvimento da linguagem, do pensamento, da concentração e da atenção da criança.

Com os resultados obtidos, conclui-se que para auxiliar o professor do $2^{\circ}$ ano do Ensino Fundamental o OA Varal de Ordenação permite um resultado mais eficiente, visto que os alunos conseguiram manipular com maior eficiência o Varal e o grau de dificuldade pode ser ajustado para cada aluno, inclusive a ordenação pode ser crescente e decrescente. $\mathrm{O}$ aplicativo possui a vantagem de oferecer a resposta ao aluno de forma automática, porém, o aluno precisa controlar o impulso de apertar os botões sem pensar ou visualizar as demais letras. Os OAs desenvolvidos podem ajudar o docente durante a fase de alfabetização dos estudantes, trazendo a experiência de manipular os objetos, desta forma, a aprendizagem torna-se mais significativa.

Como trabalho futuro pode-se implementar mais funções no Objeto de Aprendizagem do aplicativo do celular, determinando grau de dificuldade, com mais letras, colocar um contador de acertos e erros, incluir um temporizador, inserir ordenação de números, colocar uma opção que o usuário possa escolher o nível para jogar (fácil, médio e difícil), melhorar o layout da tela e incluir animações para melhorar a tratativa do erro e estimular uma nova tentativa. Quanto ao Objeto de Aprendizagem Varal de Ordenação pode-se inserir a ordenação numérica e incluir a formação de palavras.

\section{Agradecimentos}

Este trabalho foi realizado com apoio da UDESC a qual agradecemos pelo incentivo à pesquisa. Agradecemos o apoio financeiro da FAPESC, Edital FAPESC/CNPQ Nº6/2016, T.O. N $N^{\circ}: 2017 T R 1755$ - Ambientes Inteligentes Educacionais com Integração de Técnicas Learning Analytics e Gamificação e FAPESC Edital No 04/2018 - Termo de Outorga $n^{\circ}$ 2019TR585 - Processo 896/2019 - Apoio a Grupos de Pesquisa da Universidade do Estado de Santa Catarina (UDESC). 
VIII Congresso Brasileiro de Informática na Educação (CBIE 2019)

Anais do XXV Workshop de Informática na Escola (WIE 2019)

\section{Referências}

Batista, M. L. F. S. (2008) Design Instrucional: uma abordagem do design gráfico para o desenvolvimento de ferramentas de suporte à Educação a Distância. $254 \mathrm{f}$. Dissertação (Mestrado) - Curso de Pós-graduação em Design, Universidade Estadual Paulista, Bauru. Disponível em: <http://twixar.me/Nbvn>. Acesso em: 01 maio 2019.

Balbino, J. (2007) Objetos de aprendizagem: contribuições para a sua genealogia. Educação e Tecnologia, br. p.1-10. Disponível em: < http://www.dicasl.com.br/educacao_tecnologia/educacao_tecnologia_20070423.php \#.WURZ9oAzrIU>. Acesso em: 20 abr. 2019.

Filatro, A. (2008) Design Instrucional na prática. São Paulo: Pearson Education do Brasil.

Filatro, A. (2010) Design Instrucional Contextualizado: Educação e Tecnologia. 3. ed. São Paulo: Senac.

Garcia, P. T.; O., A. E. F.; Castro Junior, E. F.; Reis, R. S.; Pinho, J. R. O.; Prado, I. A.; Silva, S. M. (2015) Processo de elaboração de design instrucional para um curso auto instrucional: experiência da Una-SUS/UFMA. ABED, p.1-10. Disponível em: $<$ http://www.abed.org.br/congresso2015/anais/pdf/BD_339.pdf $>$. Acesso em: 06 maio 2019.

Guedes, G.T.A. (2011) UML 2: uma abordagem prática. 2. ed. São Paulo: Novatec.

Gomes Filho, J. (2003) Ergonomia do objeto: sistema técnico de leitura ergonômica. São Paulo: Escrituras Editora.

Ishikawa, E. C. M. (2018) Objeto virtual de aprendizagem colaborativa (Collabora): estudo na disciplina de Probabilidade e Estatística no Ensino Superior. f. Tese (Doutorado) Curso de Programa de Pós-graduação em Ensino de Ciência e Tecnologia, Universidade Tecnológica Federal do Paraná, Ponta Grossa. Disponível em: $<$ https://bit.ly/2OIGm8V >. Acesso em: 14 abr. 2019.

Kemczinski, A.; Costa, I. A.; Wehrmeister, M.A.; Hounsell, M. S.; Vahldick, A. (2012) Metodologia para Construção de Objetos de Aprendizagem Interativos. Anais do $23^{\circ}$ Simpósio Brasileiro de Informática na Educação (SBIE 2012), ISSN 2316-6533 Rio de Janeiro, 26-30 de Novembro de 2012.

Moreira, M.A. (2015) Teorias de Aprendizagem. $2^{a}$ ed. São Paulo: E.P.U.

Rived, (2018) Rede Interativa Virtual de Educação. Disponível em: $<$ http://rived.mec.gov.br/site_objeto_lis.php>. Acesso em: 20 maio de 2019.

Romiszowski, A.; Romiszowski, L. (2005) Retrospectiva e Perspectivas do Design Instrucional e Educação a Distância: análise da literatura. Revista Brasileira de Aprendizagem Aberta e a Distância, vol.3, n.1.

Tarouco, L. M. R.; Costa, V. M.; Ávila, B. G.; Bez, M. R.; Santos, E. F. (2014) Objetos de Aprendizagem: Teoria e Prática. Porto Alegre: Evangraf Ltda. 504 p. Disponível em: $<$ http://penta3.ufrgs.br/ObjetosAprendizagem/LivroOA-total.pdf $>$. Acesso em: 01 maio 2019.

Vygotsky, L. S. (1984) A formação social da mente. São Paulo: Martins Fontes. 